Received: $\quad 2020.07 .29$

Accepted: 2020.09.17 Available online: $\quad 2020.10 .27$

Published: 2020.12.15

\title{
Computed Tomography (CT)-Navigated Translumbar Hemodialysis Catheters: A 10-Year Single-Center Experience
}

Authors' Contribution: Study Design A Data Collection B Statistical Analysis C Data Interpretation D Manuscript Preparation E Literature Search F Funds Collection G

\author{
ABDEF 1,2 Tomas Jonszta \\ B 1,2 Daniel Czerny \\ ABD 1,2 Vaclav Prochazka \\ CE 3 Adela Vrtkova \\ ADE 4,5 Vendelin Chovanec \\ ADE 4,5 Antonin Krajina
}

1 Department of Radiology, University Hospital Ostrava, Ostrava, Czech Republic 2 Faculty of Medicine, University of Ostrava, Ostrava, Czech Republic

3 Department of Applied Mathematics, Faculty of Electrical Engineering and Computer Science, VSB - Technical University of Ostrava, Ostrava, Czech Republic

4 Department of Radiology, University Hospital Hradec Kralove, Hradec Kralove, Czech Republic

5 Charles University, Faculty of Medicine in Hradec Kralove, Hradec Kralove, Czech Republic
Corresponding Author: Source of support:
Tomas Jonszta, e-mail: jonszta@post.cz Departmental sources
Background:

Material/Methods:

Results:

Conclusions:

MeSH Keywords:

Full-text PDF:
In dialysis patients with exhausted usual central venous access sites, the translumbar hemodialysis catheter (TLC) provides a viable option for dialysis access. The technical success of catheter insertion, associated complications, and long-term patency of TLC were evaluated in this study.

This retrospective study included 37 patients with occluded central thoracic veins in whom 39 TLC implantation procedures were performed and 196 patients with internal jugular vein hemodialysis catheters (JVC). TLC implantation was performed as a hybrid procedure with computed tomography (CT)-navigated translumbar inferior vena cava cannulation and subsequent fluoroscopy-guided hemodialysis catheter placement.

The rates of technical success of the implantations and minor periprocedural complications were $97.4 \%$ and $10.3 \%$ in the TLC group and $98.6 \%$ and $4.2 \%$ in the JVC group, respectively. The median follow-up in the TLC and JVC groups was 673 days and 310 days, respectively. The primary-assisted patency at the 1-year and 3-year follow-up was $88.7 \%$ and $72.0 \%$ in the TLC group and $81.6 \%$ and $67.0 \%$ in the JVC group, respectively, with no statistically significant difference between the 2 groups. The incidence rate of infection-related and patencyrelated complications calculated for 1000 catheter-days was 0.15 and 0.11 in the TLC group and 0.33 and 0.25 in the JVC group, respectively.

The CT-guided implantation of the TLC is a useful option to create dialysis access with a low complication rate and satisfactory long-term patency in patients without usual venous access.

\section{Central Venous Catheters • Hemodialysis Units, Hospital • Multidetector Computed Tomography}

https://www.medscimonit.com/abstract/index/idArt/927723 


\section{Background}

There is a need for high-quality, long-term, and reliable venous access in patients receiving hemodialysis treatment. Currently, 3 basic means of venous access are available: an arteriovenous fistula (AVF), arteriovenous graft (AVG), and central venous catheter (CVC). The preferred method is AVF, which is most often created in radio-cephalic localization [1]. In developed countries, dialysis is often started with a CVC, with $10 \%$ to $40 \%$ of patients in most dialysis centers dialysed by CVC on a long-term basis [2,3]. Long-term CVC use is encountered most often in patients in whom it is impossible to create a well-functioning AVF, in particular, in patients who are older, have diabetes, or have had multiple previous cannulations. The preferred site of insertion is the internal jugular vein (IJV); while in femoral vein insertion, there is a higher risk of infection, and in subclavian vein insertion, the risk of venous thrombosis is higher $[4,5]$.

Patients with a long-term CVC use have a higher risk of venous thrombosis, development of fibrosis with subsequent venous lumen stenosis, or even occlusion. Post-catheterization subclavian vein stenoses may limit the longevity of arteriovenous accesses of the upper extremities. In patients with central vein occlusions, all other options for maintaining dialysis access must be carefully evaluated, including recanalization of thoracic central venous occlusions, placement of a Hemodialysis Reliable Outflow (HeRO) or Surfacer recanalization device, or creation of arterio-arterial prosthetic loops, methods which are reported to have good long-term patency rates $[6,7]$.

In patients without other options, the transhepatic approach, transrenal approach, and translumbar approach to the inferior vena cava (IVC) are alternatives. Since 1971, when translumbar insertion was performed for the first time, it has become the most frequently used and standardized alternative method of venous access $[8,9]$.

The standard method of performing IVC cannulation is under fluoroscopy control with navigation done according to anatomical landmarks. Occasionally, a catheter is inserted into the groin to mark the course of the IVC. Recently, CT navigation has been used to increase the safety of the procedure, allowing exact planning and real-time control of the needle trajectory to avoid injury of the clinically important structures in the retroperitoneum $[10,11]$.

We herein present the study of a cohort of patients who had dedicated hemodialysis catheters implanted in the angiography suite of our institution over a 9-year period with a hybrid procedure consisting of CT-navigated translumbar IVC cannulation followed by fluoroscopy-controlled catheter implantation.

\section{Material and Methods}

\section{Patients}

All patients who received a translumbar hemodialysis catheter (TLC) for dialysis access in our institution from 2010 to 2018 were included in the study. Patients who had a JVC inserted via IJV during the same time period were used as a reference cohort. Patient follow-up was conducted until the end of May 2019.

A total of 37 patients, 17 (45.9\%) men and 20 (54.1\%) women, received TLC during a period of 108 months. In 2 patients, an episode of translumbar catheter complete dislocation occurred and a new TLC insertion was performed. In total, 39 procedures were performed. The age range of patients with TLC was 40 to 88 years (median, 64.0 years; mean, 64.8 years). All patients had a history of past multiple femoral access complications, and bilateral brachiocephalic veins occlusion was diagnosed prior to TLC implantation.

The standard IJV catheter insertion procedure was performed in 196 patients, 113 (57.7\%) men and 83 (42.3\%) women. Catheters were inserted multiple times in 16 patients: 13 patients had 2 catheters each and 3 patients had 3 catheters each. In total, 215 procedures were performed. The age range of patients was 16 to 91 years (median, 68.5 years; mean, 64.8 years). The 2 groups did not differ significantly in the rate of comorbidities.

In the TLC patients with exhausted conventional access routes, the average time in a dialysis program before TLC placement was 6.8 years (median, 5.2 years; range, 2 to 14 years). The main cause of kidney failure was diabetic nephropathy, which occurred in 17 patients (45.9\%). There were 4 occurrences each of analgetic nephropathy, tubulointerstitial nephritis, and chronic pyelonephritis. Other causes of renal failure were polycystic kidney disease, IgA nephropathy, and staphylococcus sepsis. In 5 patients, the cause of renal failure was not reliably ascertained.

\section{Indication for catheter placement}

Standard JVCs were inserted in the patients requiring hemodialysis who were not eligible for other venous access methods at the time of the procedure.

TLCs were placed in patients with bilateral central thoracic vein occlusions, multiple femoral access complications, including iliac vein thromboses, and no other vascular access options at the time of the procedure. 


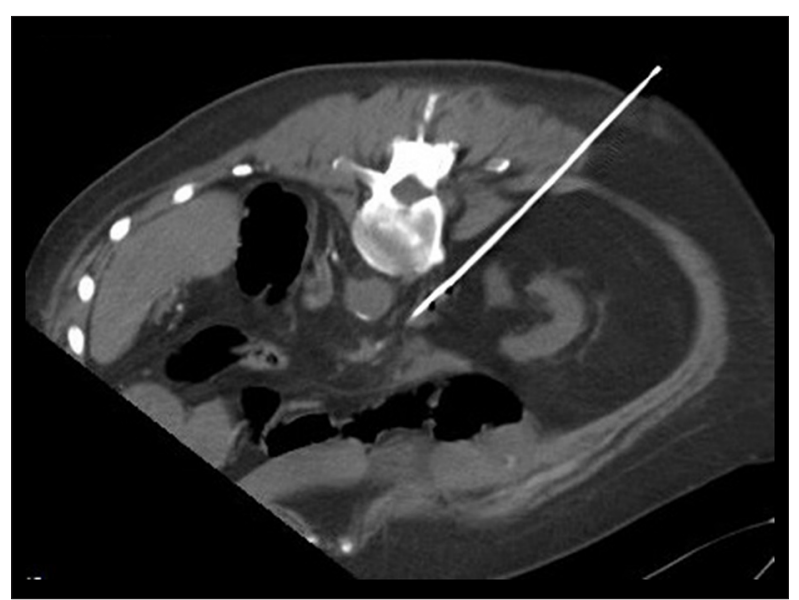

Figure 1. Computed tomography-navigated inferior vena cava puncture. Patient in prone position, oblique image along the needle plane.

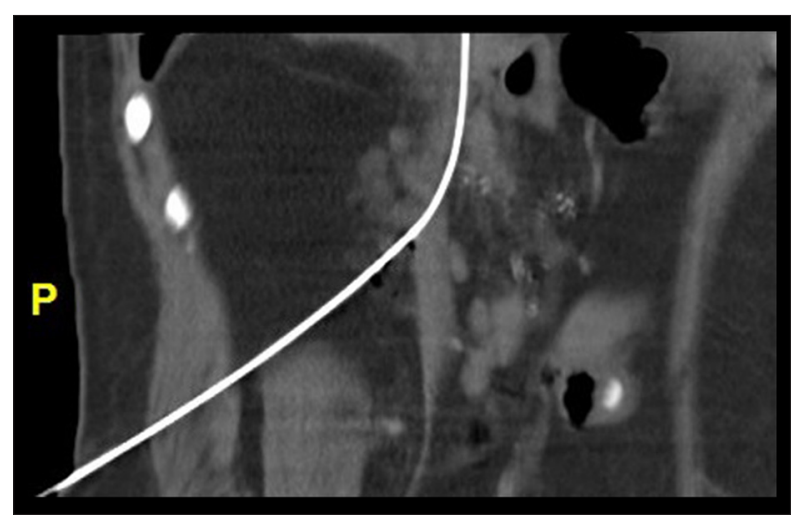

Figure 2. Computed tomography image, oblique plane. Needle and guidewire positioned in the inferior vena cava.

\section{Procedure details}

Briefly, with patients in the prone position, an access site was selected above the right iliac crest and an infrarenal IVC segment was targeted with an 18-gauge needle under CT navigation. Upon blood aspiration, a $6 \mathrm{~F}$ dilator was inserted over the guidewire and the position of the dilator within the hepatic IVC was confirmed by CT imaging (Figures 1, 2).

Next, the patients were transferred to the angiography suite and a CVC was placed under fluoroscopy control in the standard manner (Figures 3, 4). In all patients, a dedicated catheter for the translumbar approach was implanted (Split-Cath III, MedComp, Harleysville, PA, USA).

The JVCs were implanted with ultrasonography and fluoroscopy guidance via the IJV in the standard manner. In all patients, an Arrow Cannon II Plus catheter (Teleflex, Wayne, USA), 19 $\mathrm{cm}$ or $23 \mathrm{~cm}$ long, was used.

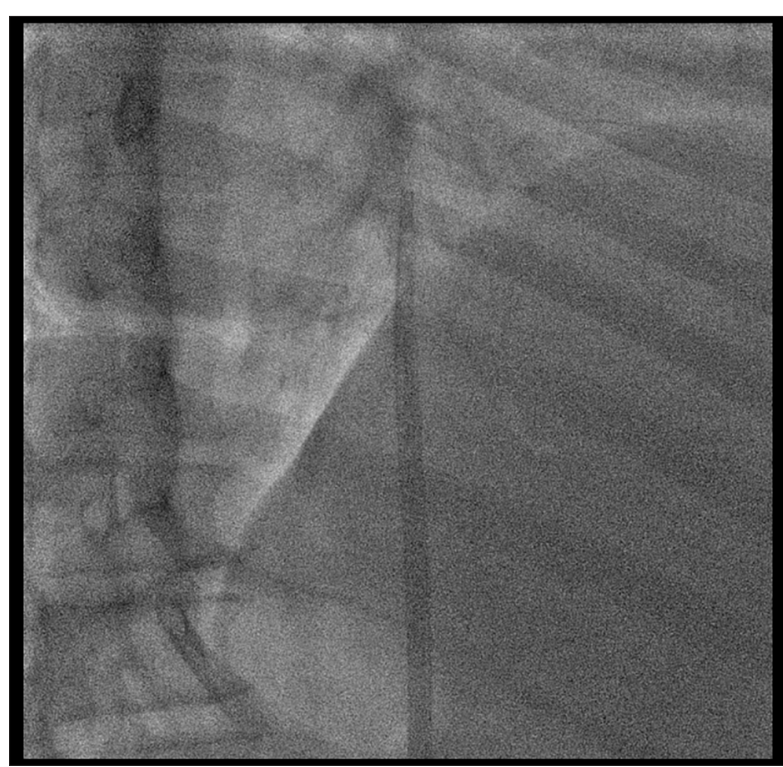

Figure 3. Fluoroscopy image upon completion of the procedure. Distal part of the catheter located in the right atrium of the heart.

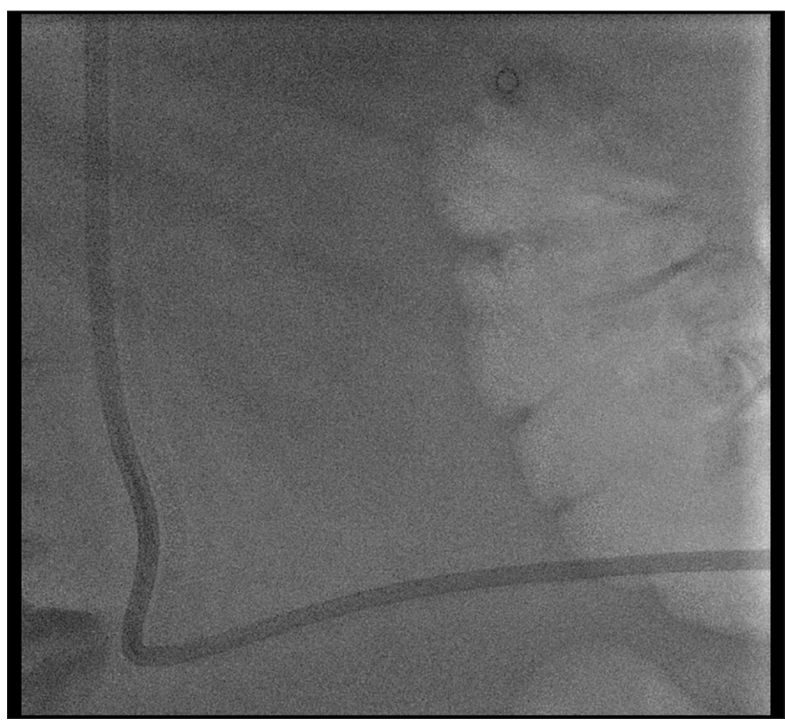

Figure 4. Fluoroscopy image upon completion of the procedure. Course of the catheter in the lumbar region.

\section{Patient follow-up}

After catheter insertion, patients were dialysed regularly in hemodialysis centers. Patients from our center were evaluated regularly in 3-month to 6-month intervals. Patients from outside centers consulted with our department to assess the need for any reintervention. Additional phone consultations were performed once per year to collect information on catheter function. In the JVC group, only patients undergoing dialysis treatment in our facility were followed up. Patients treated at neighboring hospitals were excluded from further evaluation. 
Table 1. Patients' characteristics and comorbidities.

\begin{tabular}{|c|c|c|c|c|c|}
\hline & \multicolumn{4}{|c|}{ MED $(I Q R)^{*}$ or $n(\%)$} & \multirow{3}{*}{ P\# } \\
\hline & \multicolumn{2}{|c|}{ Translumbar catheters } & \multicolumn{2}{|c|}{ Jugular vein catheters } & \\
\hline & \multicolumn{2}{|c|}{$n=37^{* *}$} & \multicolumn{2}{|c|}{$n=196 * *$} & \\
\hline Age (years) & 64.0 & $(58.0-70.0)$ & 68.5 & $(57.0-75.2)$ & 0.408 \\
\hline Body mass index & 26.4 & $(23.3-29.7)$ & 27.4 & $(24.1-32.7)$ & 0.185 \\
\hline Sex (Female) & 20 & $(54.1)$ & 83 & $(42.3)$ & 0.257 \\
\hline Diabetes mellitus & 19 & $(51.4)$ & 89 & $(46.1)$ & 0.686 \\
\hline Hypertension & 30 & $(81.1)$ & 159 & $(82.0)$ & $>0.999$ \\
\hline Ischemic heart disease & 21 & $(56.8)$ & 110 & $(56.7)$ & $>0.999$ \\
\hline Lower extremities ischemia & 12 & $(32.4)$ & 41 & $(22.7)$ & 0.292 \\
\hline Death & 23 & $(62.2)$ & 53 & $(27.2)$ & $<0.001$ \\
\hline
\end{tabular}

* The median with the interquartile range (IQR); ${ }^{*}$ the number is related to the number of patients; \# $P$ value of the Mann-Whitney test or test for the homogeneity of binomial proportions.

\section{Study endpoints}

Technical success, patient survival, primary-assisted and secondary patency, infectious complications, and catheter obstruction that led to reintervention were evaluated. Complications were divided into periprocedural, early postprocedural (occurring within 30 days after insertion), and late.

\section{Statistical analyses}

Numerical variables were expressed as the median and interquartile range or other summary statistics, such as the minimum, mean, and maximum. Shapiro-Wilk tests were performed to check data distribution. The Mann-Whitney test was used to identify significant differences between groups. Categorical variables were represented as absolute and relative frequencies (in percentages). The relationship between 2 categorical variables was analyzed with the chi-square test of independence for contingency tables, and we used the test for homogeneity of 2 binomial distributions. Further, the Kaplan-Meier curves and the log-rank test were used for survival analysis. We used $R$ software ( $R$ 3.6.1, www.r-project.org). The significance level was set to 0.05 . Survival analysis censoring was performed for patients lost to follow-up, catheter removals at the end of therapy, study termination, or patient death.

\section{Ethics}

All patients signed an informed consent, which included permission for publication of anonymized data.

\section{Results}

In the TLC group, a catheter was successfully inserted in 38 of 39 procedures, with optimal tip positioning. The technical success rate was $97.4 \%$. In 1 of the 2 patients in whom the procedure was repeated, we were unable to introduce a new catheter after the patient unintentionally pulled the original catheter out. This problem was solved by performing a femoral catheter insertion.

In the JVC group, 212 of 215 (98.6\%) procedures were successful. In 3 patients, the catheter was not inserted. In 2 patients, it was successfully inserted in the second session; and in 1 patient, further catheter insertion was abandoned.

The characteristics of patients in the study are summarized in Table 1.

In the TLC group, there were 4 (10.3\%) periprocedural complications. Two patients had retroperitoneal hematoma, which was diagnosed on CT scan directly after the complicated catheter insertion. The patients were asymptomatic and no clinical or laboratory signs of significant bleeding were diagnosed. In 1 patient, transient macroscopic hematuria developed after an unintentional atrophic kidney puncture. The 3 complications were clinically insignificant and resolved spontaneously with conservative treatment. In 1 patient, the catheter kinked in the subcutaneous tunnel. The catheter position was corrected with wire support. The latter 2 complications prolonged hospitalization of the patients by 1 day and, therefore, can be classified as grade 2 complications by the 6-grade CIRSE periprocedural complications scale [12]. 

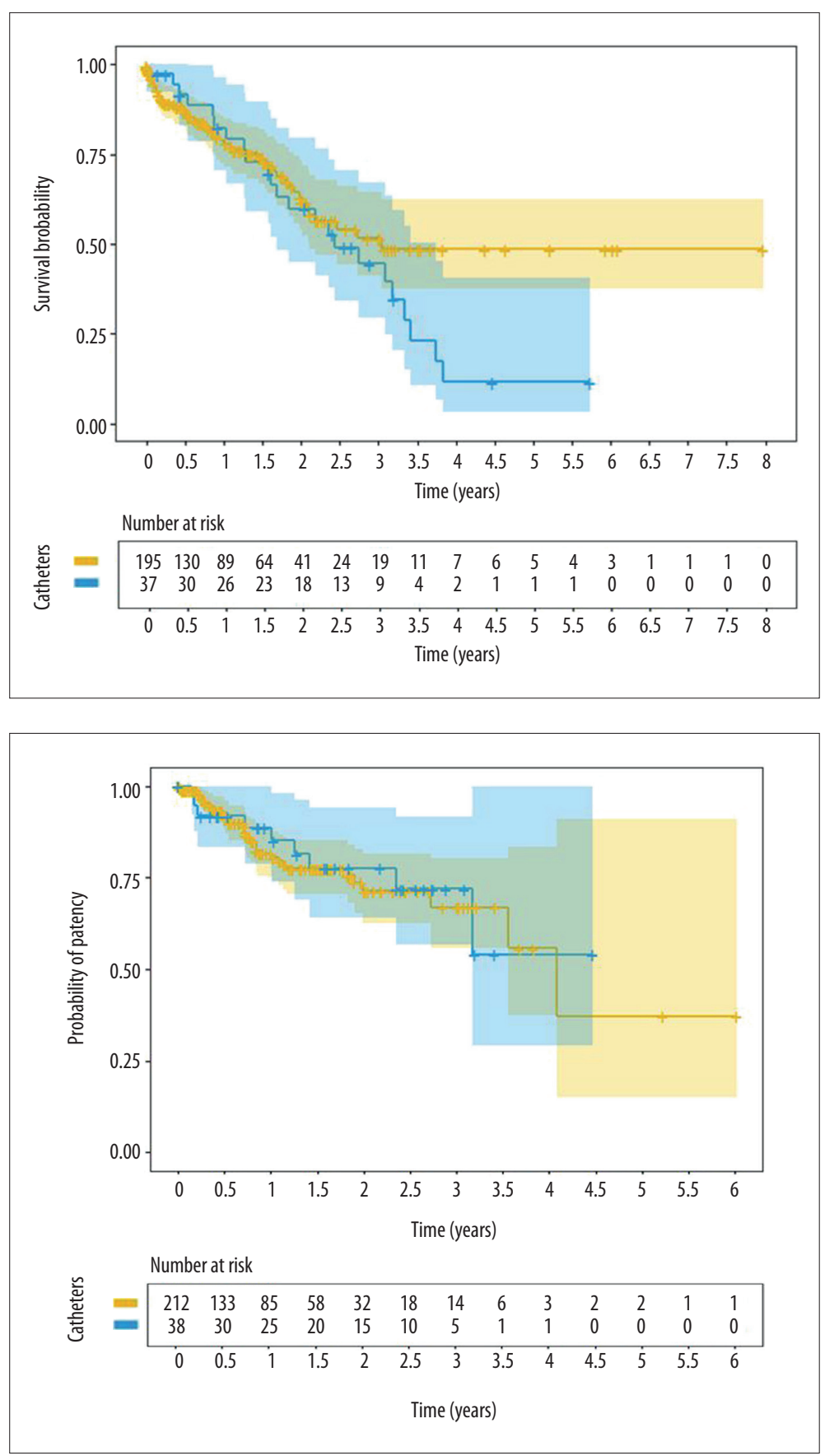

Figure 5. Cumulative patient survival with central venous catheter according to site of insertion. Translumbar catheters (blue line) and jugular vein catheters (yellow line).

Figure 6. Cumulative central venous catheter survival (primary-assisted catheter patency) according to the type of catheter. Translumbar catheters (blue line) and jugular vein catheters (yellow line).
In the JVC group, there were 9 (4.2\%) periprocedural complications of hematomas and prolonged tunnel bleeding. All 9 cases were resolved by prolonged compression without consequences.

In the TLC group, the range of follow-up was 1 to 2097 days (median, 673 days; mean 724 days). In the JVC group, the range of follow-up was 1 to 2915 days (median 310 days; mean, 453 days).
In the TLC group, 23 of 37 (62\%) patients died during the study and in the JVC group 53 of 196 (27\%) died during the study. No patient died as a result of mechanical catheter failure and subsequent inability to perform hemodialysis or because of infectious complications related to the catheter. Survival in the TLC group for 1, 2, 3, and 4 years was $82.4 \%, 59.8 \%, 44.5 \%$, and $11.5 \%$, respectively, and $78.8 \%, 63.0 \%, 51.6 \%$, and $48.5 \%$ in the JVC group, respectively. The log-rank test did not identify any statistically significant differences in patient survival time between the 2 groups ( $P$ value $=0.205$ ). However, approximately 
Table 2. List of complications according to the time of onset in the translumbar catheter (TLC) group.

\begin{tabular}{lclc}
\hline Early complications & $\mathbf{n}$ & Late complications & $\mathbf{n}$ \\
\hline Kinking & 1 & Dislocation & 5 \\
\hline Dislocation & 1 & Exit site infection & 3 \\
\hline & Sepsis & 1 \\
& Catheter loss & 2 \\
\hline & Catheter obstruction & 2 \\
\hline Total & 2 & & 13 \\
\hline
\end{tabular}

Table 3. List of complications according to the time of onset in the jugular vein catheter (JVC) group.

\begin{tabular}{|c|c|c|c|}
\hline Early complications & $\mathbf{n}$ & Late complications & $\mathbf{n}$ \\
\hline $\begin{array}{l}\text { Obstructions, } \\
\text { check-up }\end{array}$ & 6 & Sepsis & 29 \\
\hline $\begin{array}{l}\text { Dislocation, } \\
\text { reposition }\end{array}$ & 1 & Catheter obstruction & 16 \\
\hline \multirow[t]{4}{*}{ Tunnel bleeding } & 1 & Hub damage & 19 \\
\hline & & Dislocation & 1 \\
\hline & & $\begin{array}{l}\text { Right ventricle } \\
\text { prominence }\end{array}$ & 1 \\
\hline & & Catheter loss & 1 \\
\hline Total & 8 & & 67 \\
\hline
\end{tabular}

2.5 years after catheter insertion, the probability of survival was lower in the TLC group than in the JVC group (Figure 5).

In total, during the follow-up period, complications that stopped catheter patency occurred in 13 catheter placements in the TLC group ( 2 early and 11 late) and 60 catheters in the JVC group ( 8 early and 52 late). The difference between the 2 groups was not statistically significant.

Primary catheter patency in the TLC group after 1, 2, 3, and 4 years of follow-up was $76.7 \%, 65.1 \%, 59.2 \%$, and $39.5 \%$, respectively, and $69.0 \%, 51.9 \%, 51.9 \%$, and $27.7 \%$ in the JVC group, respectively.

Primary-assisted catheter patency in the TLC group after 1, 2, 3, and 4 years of follow-up was $88.7 \%, 77.6 \%, 72.0 \%$, and $54.0 \%$, respectively, and $81.6 \%, 71.4 \%, 67.0 \%$, and $55.8 \%$ in the JVC group, respectively. No significant differences were found in primary catheter patency or in primary-assisted catheter patency between the 2 groups (log-rank test, $P=0.818$ ) (Figure 6).

Secondary patency in the TLC group was $97.3 \%$ after 1 year of follow-up and $93.7 \%$ at 2, 3, and 4 years of follow-up. In
Table 4. List of complication resolving procedures performed in jugular vein catheter (JVC) group. (Catheter exchange was due to sepsis, protrusion to the right ventricle, and obstruction in 4 patients. Catheter removal was due to sepsis in 28 patients and obstruction in 2 patients.)

\begin{tabular}{|c|c|}
\hline Procedure type & $\mathbf{n}$ \\
\hline Hub exchange & 19 \\
\hline Check-up, flushing & 16 \\
\hline Catheter exchange & 6 \\
\hline Reposition & 2 \\
\hline Tunnel suture & 1 \\
\hline New JVC implantation & 1 \\
\hline Catheter removal & 30 \\
\hline Total & 75 \\
\hline
\end{tabular}

Table 5. Frequency of complications per 1000 days of followup for the 2 groups of patients, with a $95 \%$ confidence interval. No significant difference was found in the frequency of complications in the follow-up period $(P=0.169)$.

\begin{tabular}{ccc} 
Translumbar catheters $^{*}$ & Standard catheters & $\boldsymbol{p}^{* *}$ \\
\hline $0.56(0.31 ; 0.93)$ & $0.85(0.66 ; 1.07)$ & 0.169
\end{tabular}

* A total of 15 complications in 26796 days of follow-up; ** a total of 75 complications in 88389 days of follow-up; \# $P$ value of the exact Poisson test.

the JVC group, secondary patency at $1,2,3$, and 4 years of follow-up was $83.4 \%, 74.3 \%, 74.3 \%$, and $51.0 \%$, respectively. Significantly better secondary patency was found in the TLC group ( $P$ value $=0.024)$.

A total of 15 late complications in the TLC group required intervention during long-term follow-up (Table 2). Catheters were exchanged 8 times, catheter repositioning was done 5 times, and a new procedure of TLC implantation was performed in 2 cases.

During the long-term follow-up, 75 complications in the JVC group required various interventions (Tables 3, 4).

The frequency of infectious complications requiring catheter exchange or removal was 0.15 per 1000 catheter-days in the TLC group and 0.33 per 1000 catheter-days in the JVC group. Frequency of catheter patency failure requiring intervention was 0.33 in the TLC group and 0.11 in the JVC group per 1000 days. The frequency of complications is shown in Table 5. 


\section{Discussion}

According to international guidelines, AVFs and AVGs are the preferred vascular access sites for hemodialysis. The average patency of AVF is 3 years, and that of AVG is 1 to 2 years [13]. Despite widespread campaigns such as the Fistula First initiative, it is well-known that $40 \%$ of patients in the Czech Republic start a dialysis program with the CVC as a first line of venous access. In 2016 in the USA, approximately $80 \%$ of patients started dialysis with a catheter and $19 \%$ of all patients were on long-term dialysis using CVCs [14]. In our center, approximately $50 \%$ of patients need emergent dialysis with a catheter without having previous knowledge of renal failure and no advance planning for venous access, while $30 \%$ to $40 \%$ of our long-term chronic renal failure patient population have been dialysed using only CVCs over the last 10 years.

CVCs are inserted in patients who start hemodialysis suddenly and in patients missing suitable veins for AVF creation. Further, CVCs are used in hemodynamically unstable patients because their influence on circulation parameters is negligible. With CVC there is also no need for venipuncture of the AVF, which are often negatively perceived or feared by the patients.

With frequent use of CVCs for long-term hemodialysis access, the number of patients with occluded veins that preclude further catheter placement is increasing. The number of patients requiring alternative venous access is also growing, a trend that is expected to continue.

$\mathrm{CT}$ navigation enables better puncture trajectory planning and on-line needle control with sparing of nearby structures, especially the aorta, kidneys, ureter, and intestines, which in patients with atrophic kidneys, extend farther dorsally into the retroperitoneum region. One must keep in mind that the puncture canal is dilated gradually up to size $16 \mathrm{~F}$ and that a potential retroperitoneal structure injury can have serious consequences. Venous variants are more common than arterial anatomic variations and can be diagnosed more easily with the use of CT. In our cohort, 1 TLC was placed in a patient with left-sided infrarenal IVC.

Presently, CT navigation is used in more centers than ever before $[10,11]$. Originally, the TLCs were inserted under fluoroscopic control using anatomic landmarks, centering the needle at the L2-L3 vertebral bodies level. Occasionally, catheter or wire is inserted into the IVC beforehand to serve as the target point for the puncture [15]. There are no reports in the literature comparing these 2 approaches, but in fluoroscopyguided IVC punctures, the complication rate is approximately $10 \%[16,17]$. We did not find a significantly higher risk of insertion in the TLC group than in the JVC group. Similar results were published in the literature with only rare cases of selflimiting periprocedural retroperitoneal hematomas $[2,18,19]$.
Recently, results on TLC placement relying on cone-beam CT navigation were published. This technique is performed in the angiography suite and, by integrating puncture and catheter insertion in a single location, it eliminates the need for patient transfer from the $\mathrm{CT}$ intervention room to the angiography suite $[20,21]$.

In the present study, patient survival did not differ significantly between the 2 groups during the first 2 years of follow-up. However, 2.5 to 3 years after catheter insertion, the probability of survival was lower in the TLC group than in the JVC group. This could be attributed to the longer duration of hemodialysis and higher risk of comorbidity occurrence, including cardiovascular diseases, in the TLC group. The cumulative survival reported in the literature is approximately $80 \%$ after the first year and ranges from $65 \%$ to $69 \%$ after 2 years $[2,22,23]$.

One study found the cumulative primary-assisted patency of the TLCs was $73 \%$ after 1 year and $28 \%$ after 3 years [2]. In our present study, it reached $88.7 \%$ after 1 year and $72.0 \%$ at 3 years after the initial procedure, considerably better than in previously published studies. These studies had mostly small cohorts of patients and the inserted catheters were of different types. Their long-term patency, especially soon after the introduction of the TLC method, was very low (17\% in 1 study after 1 year) $[15,18]$.

The good patency rate in our study can probably be attributed to the modern type of catheter dedicated for the translumbar approach, accurate catheter placement including CT-navigated IVC puncture, and high standard of care for venous access in hemodialysis centers. Primary and primary-assisted patency in the TLC group did not differ significantly from that of the JVC group in our study. However, significantly better secondary patency was found in the TLC group. This was probably caused by a higher tolerance for leaving the TLC in place and using it even when the flow rates were suboptimal in patients in whom there was no other venous access readily available. The other factor affecting secondary patency was the ability to repeatedly cure infectious complications by intensive antibiotic therapy so that catheter removal was not indicated.

Generally, in CVC, the frequency of infectious complications is higher compared to that of AVF and AVG. In all of our patients, local skin infection at the catheter exit site was treated locally to prevent spreading along the catheter. In the TLC group, there were 3 cases of tunnel infection. In these cases, the catheter was exchanged and a new subcutaneous tunnel was created. Catheter contact with the outer environment can also be a source of sepsis, which is a feared complication.

In the TLC group, we exchanged 1 catheter because of sepsis, but we did not need to permanently remove any catheters. 
Published data declare a frequency of infectious complications of 0.8 per 1000 catheter-days, and removal of the TLC for this reason is rare. Infection of the JVC inserted via IJV is estimated at 0.3 per 1000 catheter-days [2]. In our study, the frequency of infectious complications was 0.22 in the TLC group and 0.33 in the JVC group per 1000 catheter-days. In the JVC group, we removed 28 catheters and exchanged 1 catheter because of infection. Infectious complications requiring intervention occurred in $10.5 \%$ of the TLC patients and $13.7 \%$ of the JVC patients.

In cases of catheter dislocation from a subcutaneous tunnel, we opted to reposition the catheter over the wire or exchange a catheter with new tunnel creation for good catheter fixation, based on the extent of dislocation. Neither the spontaneous complete dislocation nor the sudden removal of the catheter by the patient caused serious bleeding that might have potentially threatened a patient's life.

In the TLC group, there were no cases of mechanical damage or catheter failure. In the JVC group, there were 19 episodes of catheter hub damage. All episodes were noticed in the centers during the dialysis procedure. Damaged parts of the catheters were immediately covered with adhesives, and there was no bleeding and no air embolism. The catheter hub was exchanged for a new one in our department. The type of the catheter we use exclusively enables separate hub exchange because the spare part is available in a repair kit set. In this group, the main catheter body damage was also not encountered. No data exist in the literature on frequency of hub exchanges in this type of catheter.

For an adequate dialysis course, blood flow rates of 300 to $400 \mathrm{~mL} / \mathrm{min}$ are required, and catheter design enables the fulfilment of this criterion. The most frequent catheter-specific complication limiting flow is catheter-related sheath formation [24]. Historically, this sheath was incorrectly named the "fibrin sheath" or "fibrin cover". It was proven that the sheath is composed of cellular collagen and contains smooth muscle cells covered by an endothelial cell layer and, therefore, is not made of fibrin [25]. Its typical presentation is also called a "one-direction valve effect". Aspiration is impossible and the application or return of blood is more difficult. The sheath formation can lead to catheter thrombosis. We encountered a catheter-related sheath requiring intervention in 5.3\% of TLCS and $10.4 \%$ of JVCs.

In the present study, an insufficient flow rate was resolved in 2 patients in the TLC group by exchanging the catheter. In the JVC group, diminished flow was resolved in 22 cases through forced flushing, application of a catheter lock solution containing taurolidine and urokinase, and disruption of thrombus within the lumen by guidewire. Taurolock-U25.000 (Fresenius
Medical Care, Bad Homburg, Germany) is a solution used as a catheter lock to prevent thrombosis by filling the lumen volume. It contains urokinase (25 000 IU) and is very efficient in cases of thrombus lysis. The other components are $4 \%$ citrate, which has anticoagulation features that act on calcium in the coagulation cascade, and $1.35 \%$ taurolidine, which has a bactericidal effect even on vancomycin- and methicillin-resistant species. Taurolidine is an antimicrobial chemotherapeutic agent, which interacts with bacterial wall components by decreasing bacterial film formation on the catheter walls and reducing infectious complication rates while improving catheter patency at the same time [26].

Catheter exchange was performed in 4 patients who had a repeatedly diminished flow rate. In 2 other patients with concomitant vein stenosis, the catheter was removed and new one from a different site was inserted. We did not use continual thrombolytics infusion, snare stripping, or balloon angioplasty of the catheter-related sheath. Retrospective analyses of these techniques have not proven differences in flow restoration, complication rate, and further long-time patency in comparison with a simple catheter exchange [27].

The frequency of complications regarding catheter patency in our study was 0.11 in the TLC group and 0.25 in the JVC group per 1000 days of follow-up and was lower than the data published to date $(0.33 / 1000$ and $0.8 / 1000$ days) $[28,29]$. However, the published data refer to types of catheters that are not no longer used for translumbar hemodialysis access.

Considering the frequency of complications with CVCs, their use for dialysis access should be indicated only as a bridging method to more optimal treatment, such as transplantation or AVF creation. In our study, an AVG was created in 2 patients in the TLC group. In both cases, the functioning was not good and early thrombosis of the access site occurred. Other 2 patients were put on the transplant list; however, none received a transplant. In the JVC group, a well-functioning AVF was created in 15 patients. In 12 patients, renal transplantation was successfully performed. In 1 patient, peritoneal dialysis was introduced. Altogether, $14.3 \%$ of patients were put on a better type of treatment.

This study had limitations. First, the patient cohort size in the TLC group was relatively small. However, it should be considered that these were carefully selected patients and the cohorts published to date have not exceeded 30 to 60 patients [13,30,31]. Second, we compared 2 groups of patients with different available venous access sites, which resulted in different sites of implantation and types of dialysis catheters. 


\section{Conclusions}

Implantation of the TLC is a safe and effective method of achieving venous access for hemodialysis in patients with occluded veins in the upper body. It enables the continuation of adequate treatment and search for a potential new AVF or AVG. Longterm patency of the TLCs and their associated complication rate were not significantly different than that of standard JVCs.

\section{References:}

1. Santoro D, Benedetto F, Mondello P et al: Vascular access for hemodialysis: Current perspectives. Int J Nephrol Renovasc Dis, 2014; 7: 281-94

2. Power A, Singh S, Ashby D et al: Translumbal central venous catheters for long-term haemodialysis. Nephrol Dial Translant, 2010; 25: 1588-95

3. Lee T, Barker J, Allon M: Tunneled catheters in hemodialysis patients: Reasons and subsequent outcomes. Am J Kidney Dis, 2005; 46(3): 501-8

4. Ge X, Cavallazzi R, Li C et al: Central venous access sites for the prevention of venous thrombosis, stenosis and infection. Cochrane Database Syst Rev, 2012; 2012(3): CD004084

5. Merrer J, De Jonghe B, Golliot F et al: Complications of femoral and subclavian venous catheterization in critically ill patients: A randomized controlled trial. JAMA, 2001; 286: 700-7

6. Khafagy T, Regal S, ElKassaby M, Saad E: Early results of brachial arterioarterial prosthetic loop (AAPL) for hemodialysis. Eur J Vasc Endovasc Surg, 2016; 51: 867-71

7. Baetens TR, Rotmans J, van der Meer RW, van Rijswijk CS: A novel technique to restore access in patients with central venous occlusion using the Surfacer ${ }^{\circledR}$ Inside-Out ${ }^{\circledR}$ Access Catheter System. J Vasc Access, 2020; 21 (5): 778-82

8. Ortuno Mirete J, Conde Olasagasti J, Ruiz de Salazar D, Sanz Guajardo D, Botella García J. Haemodialysis by using percutaneous catheterization of the vena cava. Rev Clin Esp. 1971;1221: 169-172.

9. Kenney PR, Dorfman GS, Denny DF Jr.: Percutaneous inferior vena cava cannulation for long-term parenteral nutrition. Surgery, 1985; 97(5): 602-5

10. Grözinger G, Grosse U, Syha R et al: CT-guided translumbar placement of permanent catheters in the inferior vena cava: Description of the technique with technical success and complications data. Cardiovasc Intervent Radiol, 2018; 41(9): 1356-62

11. Kariya S, Tanigawa N, Kojima $\mathrm{H}$ et al: Percutaneous translumbar inferior vena cava cannulation under computed tomography guidance. Jpn J Radiol, 2009; 27: 176-79

12. Filippiadis DK, Binkert C, Pellerin O et al: Cirse quality assurance document and standards for classification of complications: The Cirse Classification System. Cardiovasc Intervent Radiol, 2017; 40(8): 1141-46

13. Kořisková Z: Cevni přistupy pro hemodialyzu. In: Krajiček $M$ et al. (eds.), Chirurgicka a intervenčni lečba cevnich onemocněni. Praha, Grada Publishing, 2007; 409-32 [in Czech]

14. United States Renal Data System. 2018 USRDS Annual Data Report. National Institutes of Health, National Institute of Diabetes and Digestive and Kidney Diseases, Bethesda, MD, 2019, https://www.usrds.org/2018/view/Default. aspx

15. Lund GB, Trerotola SO, Scheel PJ Jr.: Percutaneous translumbar inferior vena cava cannulation for hemodialysis. Am J Kidney Dis, 1995; 25(5): 732-37
16. Bennett JD, Papadouris D, Rankin RN et al: Percutaneous inferior vena caval approach for long-term central venous access. J Vasc Interv Radiol, 1997; 8: 851-55

17. Butros SR, Walker TG, Salazar GM et al: Direct translumbar inferior vena cava ports for longterm central venous access in patients with cancer. J Vasc Interv Radiol, 2014; 25: 556-60

18. Biswal R, Nosher JL, Siegel RL, Bodner LJ: Translumbar placement of paired haemodialysis catheters (Tesio catheters) and follow-up in 10 patients. Cardiovasc Intervent Radiol, 2000; 23: 75-78

19. Markowitz DG, Rosenblum DI, Newman JS et al: Inferior vena caval tesio catheter for hemodialysis. J Vasc Interv Radiol, 1998; 9(1): 145-47

20. Thakor AS, Chung J, Patel R et al: The use of cone-beam CT in assisting percutaneous translumbar catheter placement into the inferior vena cava. Clin Radiol, 2015; 70(1): 21-24

21. Kariya S, Nakatami M, Maruyama T et al: Central venous access port placement by translumbar approach using angio-CT unit in patients with superior vena cava syndrome. Jpn J Radiol, 2018; 36(7): 450-55

22. Saran R, Li Y, Robinson B et al: US Renal Data System 2015 Annual Data Report: Epidemiology of kidney disease in the United States. Am J Kidney Dis, 2016; 67(3): A7-8

23. UK Renal Registry 2017: $20^{\text {th }}$ Annual Report of the Renal Association. Nephron, 2018; 139(S1): 1-372

24. Percarpio R, Chorney ET, Forauer AR: Catheter-related sheaths (CRS): Pathophysiology and treatment strategies. Hemodialysis, 2013; 699-718

25. Xiang DZ, Verbeken EK, Van Lommel ATL et al: Composition and formation of the sleeve enveloping a central venous catheter. J Vasc Surg, 1998; 28(2): 260-71

26. Winnicki $W$, Herkner $\mathrm{H}$, Lorenz $\mathrm{M}$ et al: Taurolidine-based catheter lock reg imen significantly reduces overall costs, infection, and dysfunction rates of tunneled hemodialysis catheters. Kidney Int, 2018; 93(3): 753-60

27. Janne D'othée B, Tham JC, Sheiman RG: Restoration of patency in failing tunneled hemodialysis catheters: A comparison of catheter exchange, exchange and balloon disruption of the fibrin sheath, and femoral stripping. J Vasc Interv Radiol, 2006; 17(6): 1011-15

28. Wang J, Laberge JM, Chertow GM et al: Tesio catheter access for long-term maintenance hemodialysis. Radiology, 2006; 241(1): 284-90

29. Duncan NDC, Singh S, Cairns TD et al: Tesio-Caths provide effective and safe long-term vascular access. Nephrol Dial Transplant, 2004; 19(11): 2816-22

30. Rajan DK, Croteau DL, Sturza SG et al: Translumbar placement of inferior vena caval catheters: A solution for challenging hemodialysis access. Radiographics, 1998; 18(5): 1155-67

31. Romero Jaramillo A, Ortega D, Uribe R, Uriza F: Translumbar haemodialy isis catheter placement. Single center 54 months experience at hospital universitario San Ignacio. ECR, 2014/C-1538, https://pdfs.semanticscholar. org/d7ea/e55c2527217bc184c15b48c603d182b9433d.pdf 